\title{
Beginner Teachers' conceptions of a successful lesson in English secondary schools: structure and implications
}

\author{
Guy Durden \\ Department of Curriculum, Pedagogy and Assessment, UCL - Institute of Education, \\ London, UK
}

\begin{abstract}
This phenomenographic study describes qualitative differences in Beginner Teachers' (BTs') conceptions of a phenomenon central to their routine experience of teaching: the successful lesson. Conceptions were found to be comprised of two independently related components, the structure of the successful lesson and its purpose. Evidence on the structure supports the adoption of a systems approach to BTs' thinking about lessons. Evidence on purpose confirms previous research into conceptions of learning. It was found that a sophisticated understanding of learning is not sufficient to ensure a sophisticated understanding of a successful lesson. These results add to teacher educators' pedagogical content knowledge.
\end{abstract}

\section{Keywords}

Phenomenography, conceptions of teaching, conceptions of learning, lessons

Department of Curriculum, Pedagogy and Assessment

UCL - Institute of Education

20 Bedford Way

London

WC1H 0AL

E-mail: g.durden@ucl.ac.uk 


\section{Introduction}

It is often assumed that the sophistication of teachers' thinking has a major impact on their teaching strategies and therefore on the quality of student learning (e.g. Trigwell \& Prosser, 1999). It follows that teacher education programmes should prioritise the development of Beginner Teachers' (BTs') thinking. But thinking about what? Given the complexity of teaching it seems likely that there will be a number of important phenomena to focus on. This implies that BTs will need both a sophisticated understanding of individual phenomena, but also a sophisticated understanding of the relationships between phenomena. To be effective in their role, teacher educators will also need a good knowledge of how BTs understand important phenomena in teaching and the relationships between them.

A large number of researchers have identified teaching and learning as two phenomena that are of critical importance (e.g. Wood, 2000; Entwistle, 2007; Boulton-Lewis et al., 2008; Tsai \& Kuo, 2008; Paakari et al, 2011; Taylor \& Booth, 2015). These researchers have often worked within the phenomenographic research tradition, developing punchy descriptions of qualitative differences in ways of understanding teaching and learning (referred to as conceptions). A few researchers have extended this work to explore relationships between conceptions of teaching and conceptions of learning (e.g. Prosser et al., 2005).

This study focuses on a different (although related) phenomenon: the successful lesson. The successful lesson is an immediate and tangible aspect of teachers' (and BTs') routine experience of teaching and learning. This is partly because, as an organisational device, the lesson is a near ubiquitous feature of education in secondary schools in England (and elsewhere), with teachers (and BTs) drawing up lesson plans, describing their day in terms of numbers of lessons and following a timetable divided into lessons. It is also because 'success' is a key aspect of teachers' (and BTs') motivation and identity, with teachers aiming to teach successful lessons, drawing personal and professional satisfaction from teaching them and often being judged by senior managers and inspectors on how successful their lessons are.

This study aims to describe BTs' conceptions of a successful lesson and to identify differences between more and less sophisticated conceptions. Since conceptions of teaching and learning are likely to be related to conceptions of a successful lesson, the study also aims to cast light on the way in which BTs' conceptions of these phenomena are related. The main possibilities are: i) that there is nothing distinctive about the successful lesson and that conceptions of this phenomenon are identical (or very similar) to previously described conceptions of teaching and learning, ii) that there is something distinctive about the successful lesson, but conceptions of it are separate from conceptions of teaching and learning and, iii) that conceptions of teaching and learning are embedded in conceptions of a successful lesson (or vice versa).

Findings in relation to these issues will contribute to teacher educators' knowledge of: i) the way in which BTs understand prominent aspects of their experience of teaching and, ii) the relationships between BTs' understandings of those prominent aspects. This knowledge is likely to be of significance in the design and implementation of teacher 
education programmes and the broad implications of the study's findings for teacher education are discussed in this paper.

In line with previous research in the field, this study adopts a phenomenographic approach to the analysis of BTs' conceptions of a successful lesson. Evidence is drawn from 23 BTs studying for teacher accreditation in economics and business studies at a top rated English University in 2016/17. To provide background, the next section briefly summarises the findings of previous phenomenographic research into conceptions of teaching and learning and explores these in the context of the successful lesson. After this results are presented and discussed.

\section{Phenomenography, conceptions of teaching and learning and the successful lesson}

Phenomenography aims to gather evidence of differences between the ways in which people understand the same phenomenon (Marton, 2015). Differences are assumed to be visible in the structure of peoples' thinking. This means that less sophisticated ways of thinking are usually embedded within more sophisticated ways of thinking. As a result, the most common outcome of phenomenographic research is a hierarchy of logically related descriptions of conceptions of a phenomenon (Åkerlind, 2012).

Phenomenography has been very successful in identifying differences between conceptions of teaching and conceptions of learning. Studies of conceptions of teaching typically describe a hierarchy ranging from knowledge transmission with a focus on teacher activity at the bottom, and conceptual change with a focus on student activity at the top (e.g. Trigwell \& Prosser, 1996; Kember, 1997; Gonzalez, 2011; Taylor \& Booth, 2015). Studies of conceptions of learning typically distinguish between the acquisition of knowledge at the lower levels and the constitution of knowledge at the higher levels. In other words, they move upwards in sophistication from an increase in the quantity of knowledge to an increase in its quality through conceptual change (e.g. Marton et al., 1993; Rossum \& Hamer, 2010).

There has been good consistency between the conceptions discovered in different educational contexts, in different subject disciplines, amongst different groups of teachers (e.g. BTs and experienced teachers) and over time (e.g. Wood, 2000; Paakari et al, 2011; Taylor \& Booth, 2015). The results chime with non-phenomenographic studies of both experienced teachers' and BTs' conceptions (e.g. Cheng et al., 2009; Chen et al., 2012; Swinkels et al., 2013; Tigchelaar et al., 2014).

Descriptions of BTs' conceptions are powerful for teacher educators because they make qualitative differences in BTs' understanding explicit. This can underpin the design of teacher education programmes and the associated learning activities. It can also make clearer the degree of conceptual change that such programmes and activities bring about in BTs. However, the findings are restricted in the extent to which they reflect the complexity of teaching, because they do not directly address the impact of relationships with other important phenomena in BTs' experience of teaching. In response to this, a small body of 
research has developed exploring the relationships between conceptions of teaching and learning and conceptions of other important phenomena such as subject knowledge (e.g. Trigwell et al., 1999; Prosser et al., 2005).

This study extends this research to another phenomenon that appears prominent in BTs' everyday experience of teaching in an English secondary school: the successful lesson. This prominence arises partly from BTs' fundamental motivation to teach high quality lessons and partly from the ubiquity of the lesson as 'an organisational device to bring students into contact with the curriculum' (Desforges, 2015, p.xvi). In English secondary schools, the school day is typically divided into between 6 and 8 lessons lasting between 45 and 60 minutes. Experienced teachers usually teach around 20 to 25 lessons a week to a range of differently aged groups of students. This means that, by necessity, teachers have to package their efforts to promote student learning into what are often relatively short episodes, and also have to account for the periods of time that occur between lessons. In other words, they have to work out how the students' learning in any single lesson fits in to any learning that may occur over time. These constraints open up the possibility of a difference emerging between teachers' understandings of teaching and learning and their understandings of an individual successful lesson. BTs generally teach fewer lessons than experienced teachers, but are still subject to the same basic constraints.

In order to understand more about the potential relationships between BTs' thinking about the successful lesson and their thinking about teaching and learning, it is useful to look at how the relationship between teaching and learning has been treated in previous research. There have been two broad approaches. In one approach, teaching and learning are treated as if they are two distinct phenomena. This allows the exploration of associations between the two sets of conceptions. A high degree of correlation between the sophistication of conceptions of teaching and the sophistication of conceptions of learning has been established in some studies (e.g. Trigwell \& Prosser, 1996; Gonzalez, 2011). In a second approach, teaching and learning are assumed to be practically inseparable. They are treated as if: i) they are both embedded in a single phenomenon (referred to as 'teaching and learning') or, ii) one (usually learning) is embedded within the other.

Prosser et al. (2005) take the former approach. They propose that conceptions of teaching and learning can be divided into 'referential' components (which might broadly be seen as qualitatively different conceptions of learning) and 'structural' components (which might broadly be seen as qualitatively different conceptions of teaching). Taylor and Booth (2015) represent the alternative approach. Their study claims to be researching conceptions of science teaching but their descriptions of conceptions seem to include aspects of learning. For example, one conception describes students as 'receiving' science knowledge, in another as 'understanding' it and in another as 'constructing' it (Taylor \& Booth, 2015 p.1308). In contrast to Prosser et al. (2005), Taylor and Booth imply that learning is embedded within the phenomenon of teaching.

These studies provide an indication of how a successful lesson might be related to teaching and learning. This is important because this relationship affects teacher educators understanding of the structure of BTs' knowledge, and therefore the way in which teacher education is organised. In straightforward terms, if a successful lesson is distinct from 
teaching and learning then, other things remaining equal, it makes sense for teacher educators to focus on developing the sophistication of BTs' understanding in both simultaneously. Alternatively, if teaching and learning is embedded within the broader phenomenon of a successful lesson, then increasing the sophistication of BTs' knowledge of conceptions of teaching and learning may have restricted impact on the effectiveness of BTs' teaching since that knowledge is mediated through conceptions of a successful lesson. This means it may make sense to prioritise the development of conceptions of a successful lesson since this will naturally include teaching and learning. The alternative approach of focusing on teaching and learning may have less of an immediate impact on the quality of teaching without an understanding of the wider phenomenon of a successful lesson.

One strand of phenomenography that casts a light on the separateness and connectedness of phenomena is the research on the impact of context on conceptions of teaching and learning (e.g. Koballa et al., 2000; Lindblom-Ylanne et al., 2006; Yung et al., 2013). This research shows how underlying similarities with the results of the general research into conceptions of teaching and learning are still 'visible' in different contexts, although in a modified form. It provides evidence for the possibility that conceptions of teaching and learning could be mediated by conceptions of a successful lesson in a similar way.

For complex phenomena such as a successful lesson, a question arises about the nature of the relationship between the components of conceptions. Again, a review of the research into conceptions of teaching and learning is instructive. On one view, the relationships between the different aspects that make up a conception are fixed. In Prosser et al. (2005), the phenomenon of teaching and learning is conceptualised as a single phenomenon which contains elements of teaching (referred to as structural aspects) and elements of learning (referred to as referential aspects). These two aspects are presented as being in a fixed relationship. For example, 'information transfer' (referential) is a feature of 'teacher focused' (structural) teaching, but it is not possible for it to be a feature of 'student focused' teaching. Another possibility is that the relationship between components of conceptions is not fixed and components are independently variable. Prosser et al. (2005) did not find evidence that teachers could possess a high level conception of teaching and yet have a low level conception of learning (or vice versa) but it is theoretically possible that they might have. Evidence for this possibility comes from a study examining the context of the phenomenon of price in economics. Durden (2018) has shown how conceptions of context can vary independently of conceptions of price, although both are inextricably linked. Conceptualising the context as a separate phenomenon to the phenomenon itself was a key aspect of this study. This follows the approach taken by Willhelmson et al. (2011) and Taylor \& Booth (2015).

This study explores the issues above in relation to what is assumed to be a prominent aspect of BTs' experience of teaching: the successful lesson. It aims to describe BTs' conceptions of this phenomenon and discover what kind of phenomenon the successful lesson is understood to be. This means establishing first, whether it is separate from conceptions of teaching and learning or whether these phenomena are embedded within it, and second if they are embedded, whether the components of conceptions are in fixed or independent relationships with each other. 


\section{Method}

\subsection{Research design}

This study adopted a phenomenographic methodology in order to identify and describe qualitative differences between BTs' understandings of a successful lesson. The qualifier 'successful' made it easier for BTs to provide in-depth responses to questions about lessons because it introduced a sense of purpose related to their own motivations for teaching. This follows the justification provided by other studies that have examined teachers' conceptions of 'good' teaching (Yung, 2013) or 'excellent' teaching (Chen, 2012), rather than 'teaching' in general.

This study drew on evidence from semi-structured interviews and written responses that aimed to expose the widest possible variation in BTs' understanding. Descriptions of conceptions of a successful lesson emerged after an iterative analysis conducted by a small team of researchers. The study adhered to the British Education Educational Research Association (2011) standards for ethical research. This involved seeking active consent from participants, minimising any negative impacts on them and assuring them of confidentiality.

\subsection{Context and participants}

This study involved graduates of economics and business studies completing a Post Graduate Certificate of Education in economics or business studies at an English university in 2016/17. This nine month programme led to official teacher accreditation for the teaching of $14-19$ year olds and involved at least 120 days practicum in English secondary schools, preparing and teaching lessons, and 60 days in university.

Twenty three participants were involved which represented the entire cohort of economics and business studies BTs at the university in that year. This group was chosen because it contained students with diverse backgrounds and was therefore more likely to reveal the full range of variation in BTs' understanding. The group had degree classifications ranging from first class (the top level of classification) to lower second (the third level of classification and the minimum acceptable for entry into the PGCE programme). Degrees were in a wide range of subjects related to economics and business including management, accounting, econometrics and marketing. BTs were aged between 23 and 42 and were from a variety of different socio-economic backgrounds. Eight had come straight from undergraduate study and the others had some experience of work in a number of different sectors before beginning the course. There were 11 females and 12 males involved in the study. 


\subsection{Data collection}

About half way through their programme, all 23 BTs were asked to complete a written questionnaire and 8 BTs were randomly chosen to be interviewed. This approach allowed the validity of written evidence to be checked through a comparison with interview data. In order to ensure that the quantity of data remained manageable, not all participants were interviewed. BTs were given 50 minutes to respond to the written questionnaire. Most wrote between 1000 and 1200 words. The questionnaire consisted of the following 5 questions:

1. Think about a successful lesson that you have taught. Write a short description of this lesson. What was the topic? What was the group like? What were the main activities?

2. Now think about a less successful lesson that you have taught and write a short description of this lesson.

3. Bearing in mind these two lessons, what are the key indicators you use in deciding how successful a lesson is?

4. Why are these good indicators to use?

5. Please explain why the successful lessons you have taught are successful.

Since, like other teachers, BTs' understandings of teaching are often tacit (Eraut, 2000), Questions 1 and 2 aimed to encourage BTs to bring their experience of teaching to the forefront on their minds. The contrast between a successful and a less successful lesson was designed to highlight variation that would provoke deeper thinking that could be drawn on in later answers. In order that researchers could check on the reliability of earlier answers, as well as prompt BTs to include anything they may have missed, question 5 approached the same issue as questions 3 and 4 (although in a slightly different way).

The interviews were conducted by an experienced phenomenographic researcher. They lasted between $45-60$ minutes and took place on the same day as the written questionnaire. This ensured that BTs' thinking was fresh in their minds and they could draw upon their responses to the questionnaire. Following Åkerlind (2012), the researcher asked a combination of open questions (to establish what BTs' thinking about a successful lesson was) and situated questions (to establish practical examples to illustrate that thinking). As in the questionnaire, contrast was introduced to encourage deeper reflection. For example, BTs were asked to describe whether and how their thinking about successful lessons had changed over time. The researcher followed up planned questions with supplementary questions to probe BTs' thinking and elicit any as yet uncovered aspects. All interviews were fully transcribed.

\subsection{Data analysis}

Eight researchers were involved in this study to bring different perspectives to the analysis and increase the chances of capturing all the meaning in the data (Trigwell, 2000). The study was led by an experienced phenomenographic researcher with the support of two university tutors (with extensive experience in business studies and economics teacher education) and 5 BTs who acted as researchers. 
The analysis took place for just over 6 months. This relatively lengthy time frame gave researchers the opportunity to look at the data from different perspectives and at different times (Akkerlind, 2012). The analysis was divided into 3 phases:

- Phase 1 - an intensive initial 6 weeks involving all researchers

- Phase 2 - a further 4 months involving mainly the lead researcher

- Phase 3 - a final 1 month phase with two university tutors

\subsubsection{Phase 1}

In the first 6 week phase, researchers met for three full days in weeks 1, 3 and 6 . To keep the amount of data manageable and because most of the researchers were new to phenomenography, the Phase 1 only examined questionnaire responses and introduced them gradually over the 6 weeks. The priorities were to maintain an openness to the full range of possible meanings in the data and not to look for too much in the data at once. As a result, the first meeting involved a general introduction to phenomenography and some initial analysis of 5 randomly selected responses. The second meeting focused on drafting categories (drawing on 13 responses). At the last meeting, an additional 5 responses were analysed to check the emerging descriptions of conceptions.

Before each meeting, researchers worked independently, repeatedly reading and rereading BTs' responses with a high sensitivity to differences in their ways of thinking about successful lessons. Researchers drew up draft descriptions of conceptions based on their reading of the questionnaire responses, trying as far as possible to bracket their own perspectives and not impose these on the data (Richardson, 1999). They then reviewed and redrafted these in the light of repeated analysis of the responses. This involved a combination of referring to particular illustrative sections of responses, whilst maintaining a holistic reading of each response. Researchers treated the data as 'pooled' (Marton \& Booth, 1997), recognising that BTs might demonstrate a number of conceptions in their responses. Throughout the process researchers were aware of the importance of distinguishing between the words BTs used and their meaning. In the meetings researchers discussed their draft conceptions in pairs and then with the group as a whole. Some heated discussions occurred during which frequent reference was made to BTs' original responses in order to clarify what they might have really meant. These discussions acted as a powerful stimulus for further revisions after the meetings.

During the second meeting, researchers reached a consensus that there were 9 broad conceptions of a successful lesson but also agreed that there were an unresolved set of ideas relating to its purpose. After the third meeting this was reduced to 6 conceptions: i) external factors, ii) human relationships, iii) lesson planning, iv) engagement, v) flow/coherence and, vi) learning for all. In addition, 4 conceptions relating to the purpose of a successful lesson were identified. A tentative structure in relation to the 6 conceptions was proposed, although there was less agreement about how the ideas related to purpose fitted in.

The last part of the final meeting involved a further consideration of the possible structural relationships between conceptions (Ashworth \& Lucas, 2000). Phenomenography assumes 
that there is a logical structure to peoples' conceptions that is most frequently revealed in a linear hierarchy of inclusiveness (Åkerlind, 2012). In this study, the Structure of the Observed Learning Outcome (SOLO) taxonomy (Biggs, 1996) was used to guide the process of developing the structure of conceptions. The SOLO taxonomy is a way of describing the increase in complexity that a learner experiences when they learn about a phenomenon. It consists of 5 levels: i) pre-structural, ii) uni-structural, iii) multi-structural, iv) relational and, v) extended abstract. The first three levels represent an increase in structural complexity in terms of a consideration of an increasing number of the factors that bear on a phenomenon. This moves from no factors at the pre-structural level to many factors at the multi-structural level. Levels (iv) and (v) are qualitative restructurings of level (iii). 'Relational' refers to the integration of different concepts with each part contributing towards the overall meaning. 'Extended abstract' refers to the reframing of the relational at a higher level to ensure generalisation to new topic areas.

The SOLO taxonomy chimes well with phenomenography since it focuses on the meaning of learning in relation to a particular learning situation, rather than in relation to general development stages (as might be the case, for example, with a Piagetian approach). A limitation is that it consists of predetermined categories that might not fit neatly with evidence from BTs. To help counter this, researchers in this study aimed to strike a balance between applying the SOLO taxonomy as a way of structuring BTs' conceptions and being alive to the possibility that it might not provide a complete description of that structure.

\subsubsection{Phase 2}

In the second phase of the analysis the experienced researcher worked solely with the 8 interview transcripts and the draft conceptions from the first phase. Following the previous pattern, the first two months or so were spent focusing more on the descriptions of conceptions and the second 2 months more on the structure. At least 10 redrafting cycles occurred during this period. At no point did the search for a structure based on the SOLO taxonomy exclude the possibility of revising descriptions of conceptions (Åkerlind, 2012). At some times conceptions were revised in the light of the structure, at others the structure was revised in the light of the conceptions. Towards the end of the 4 months the frequency and scale of redrafting began to reduce and a stable set of conceptions was established.

\subsubsection{Phase 3}

In the final phase, to help increase the reliability of the results, the 2 university tutors involved in the study were each allocated 4 interview transcripts to review. They identified aspects of the transcripts that aligned with the proposed conceptions and aspects that did not. The 2 tutors then swopped transcripts and repeated the process, before discussing findings with the main researcher. As a result of this process, both the main descriptions and the overall structure of conceptions were confirmed. Two amendments were suggested which after a review of 10 written questionnaires by the main researcher were accepted as a more complete description of BTs' conceptions. These were: i) two subcategories relating to the purpose of a successful lesson were merged and, ii) the labelling of two conceptions related to the structure of a successful lesson was refined. 


\section{Results}

\subsection{BTs' conceptions of a successful lesson}

The study identified twelve conceptions of a successful lesson, each made up of two different components (Table 1.0). One component related to the purpose of a successful lesson, defined as the extent to which different elements of a lesson are interrelated (Rows A - C). The other related to its structure, defined in terms of the complexity of understanding of content knowledge (Columns $1-4)$.

The purpose and structure of a successful lesson were found to consist of qualitatively different and logically related components. In Table 1.0, rows and columns are arranged in order of increasing sophistication from $\mathrm{A}$ to $\mathrm{C}$ and from 1 to 4 . This makes it possible to distinguish between a less sophisticated conception of a successful lesson, such as A1, and a more sophisticated conception, such as $\mathrm{C} 4$.

Table 1.0 - Beginner Teachers' conceptions of a successful lesson

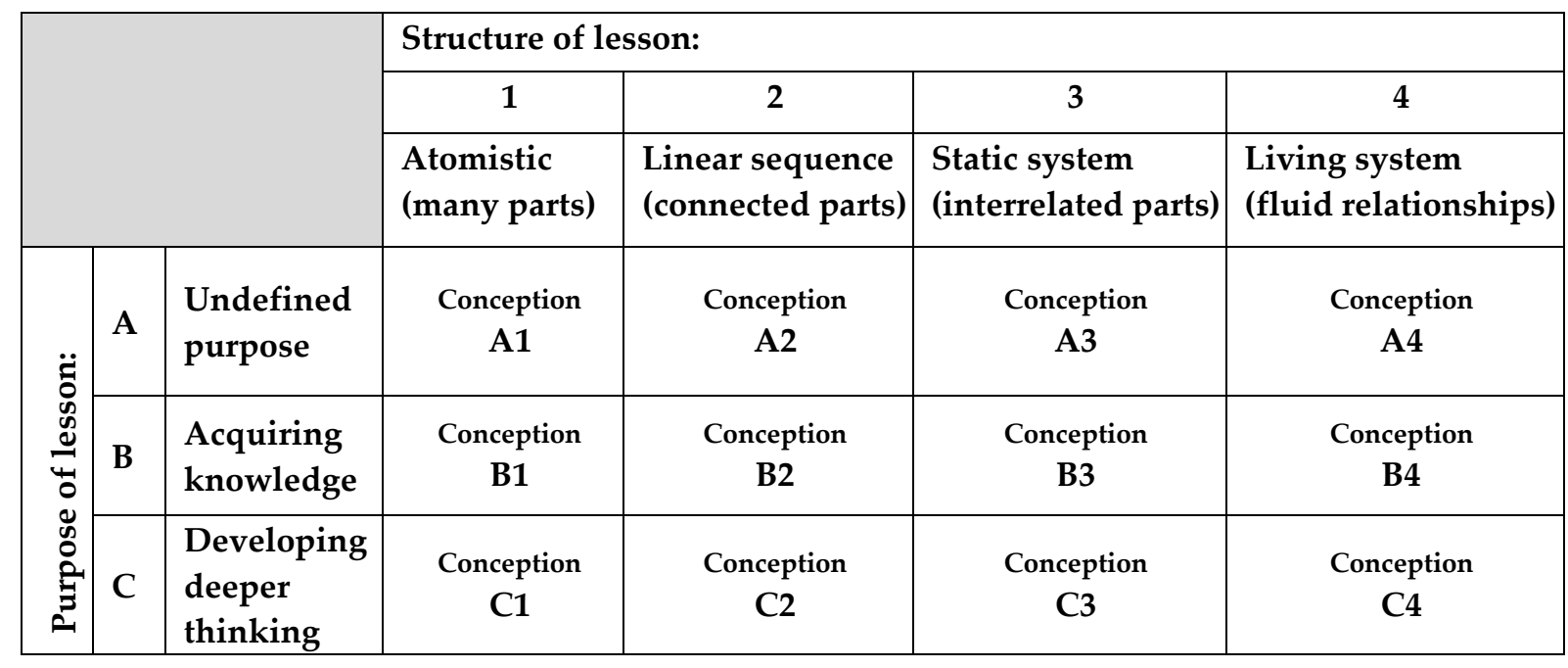

Columns $1-4$ represent the successful lesson as a system. At the lower level, the system consists of many disparate, largely unrelated parts that must occur simultaneously for the lesson to be successful (Column 1). Columns 2 - 4 represent increasing complexity, from a linear sequence of parts of the lesson (Column 2) to a more complex network of relationships between those parts (Columns 3 and 4). Column 3 envisions the system as a fixed set of relationships between different parts, Column 4 as a living, organic set of relationships. In other words, Column 3 imagines a successful lesson as a complex problem with a fixed solution (as a puzzle to be cracked) whilst Column 4 imagines it in terms of fluid linkages between parts that can develop and change. In terms of the SOLO taxonomy, Column 1 might be considered multi-structural. Columns 2, 3 and 4 are more relational but distinguished by an increasing degree of complexity in those relationships.

Rows A - C focus on the purpose of a successful lesson. Row A represents the idea that a successful lesson has a purpose, but does not specify what that purpose is. By contrast, 
Row $B$ defines purpose in a straightforward way, as the acquisition of declarative knowledge, whilst Row $\mathrm{C}$ defines it in a sophisticated way, as the development of deeper thinking. In terms of the SOLO taxonomy, Row A is at the pre-structural level, Row B is structural and Row $\mathrm{C}$ more related to relational and extended abstract levels.

\subsection{Evidence of BTs' conceptions of a successful lesson}

To illustrate BTs' conceptions, quotations of various lengths from interview transcripts and written questionnaires are presented below. Following the principles of phenomenography the aim is to demonstrate the existence of these conceptions rather than their frequency. Quotations have been chosen to illustrate important aspects of conceptions rather than necessarily reflect the whole conception. For brevity, differences between components of conceptions are highlighted, rather than examples of all 12 conceptions being provided. Evidence of differences between conceptions of the structure of a successful lesson (i.e. Columns $1-4$ ) is presented before evidence of differences between conceptions of purpose (Rows A - C). Finally, contrasting quotations are examined to illustrate the relationship between structure and purpose.

BTs with conceptions in Column 1 (i.e. Conceptions A1, B1 or C1) displayed an atomistic understanding of structure and often simply listed the parts that make up a successful lesson. These typically included: i) BTs' subject knowledge, ii) students' enjoyment of the topic, iii) the right level of subject content, iv) students' engagement, v) the pace of the lesson and, iv) student behaviour. BTs often illustrated these points with examples or provided basic explanations of the importance of each part. For example, one BT wrote 'if students enjoy it, the lesson is more likely to be successful.....not all students like financial calculations, for example'. Connections between parts were hardly ever made by BTs with this level of understanding.

By contrast, BTs with conceptions in Column 2 (i.e. Conceptions A2, B2 or C2) identified linear connections between parts of the lesson. For example, they often focused on lesson planning, highlighting the sequence of parts of the lesson and giving a sense of completing these parts within a time period. One BT went into considerable detail about a generic lesson plan describing having 'folders on the desks' and 'pre-printed starter activities' along with 'varied activities that included pair and group work' and 'a mini-plenary' that 'often happened half or two thirds of the way through the lesson and always a plenary at the end'. This BT had a powerful sense that there was a blue print for a successful lesson which should involve different parts being present at different times. Conceptions in Column 2 were typified by the presence of 'rules' for the sequencing of teaching a successful lesson. For example, that there should always be a plenary activity at the end.

BTs displaying a more sophisticated 'integrated system' understanding of the successful lesson (Column 3) saw it in terms of a complex interplay between factors. For example, one BT explained that:

I think the manifestation of a successful lesson is too complex to define in single indicators or multiples of these indicators. It is a mixture, almost like a recipe. Sometimes you change 
the mixture to taste..... Most of the ingredients to a successful lesson are usually the same but applying the exact same indicators doesn't always work.

This BT uses the metaphor of the recipe to explain how the same ingredients can be combined in different ways to give different outcomes. The idea of a 'mixture' stands in contrast to the idea of a sequence that characterises Column 2 conceptions. A number of BTs made use of an overarching idea which could draw together the different aspects of the lesson. For example, one BT described a list of components that would characterise a successful lesson then wrote that 'throughout all this, (the teacher should) remember what the purpose of the lesson is and have mini-plenaries to achieve the purpose'. The phrase 'throughout all this' implies that the successful lesson depends on the interplay between purpose and teaching strategy. It presents a successful lesson as being multi-dimensional and layered. Other BTs used the concept of 'engagement' to link together the different aspects of what they saw to be a successful lesson. One wrote:

If students are engaged in the activities that are purposeful they will not be disturbing other students. If the activities are differentiated this will ensure that all students will be able to ...... engage in the lesson. By engaging students with the topic, it will get them to think deeper about the topic and get them excited about it.

A living system understanding of a successful lesson (Column 4) was characterised by the same type of complexity but relationships were seen as being more flexible and organic. BTs with this perspective emphasised how the lesson might change when it was in progress. They highlighted risk taking in their descriptions of a successful lesson and the benefits of balancing planning (indicative of Column 2) with spontaneity in the lesson. One BT referred to a list of components of a successful lesson in the following way:

In addition to the points discussed above these indicators allow me to build up a continuously developing framework for how much information the class has actually learned against how they have been taught. This in turn allows me to 'course correct' and address each individuals' learning needs rather than simply delivering the content of the specification lesson by lesson.

The ideas of a 'continuously developing framework' and 'course correct(ion)' describe the lesson as an evolving entity where different 'indicators' are at play, but in a fluid way. Some BTs expressed this fluidity in the context of the wholeness of the living system. For example, one BT described the best lesson he had ever seen:

(It) was a primary school lesson....... I think it was a maths lesson.....she (the teacher) had about six or seven things going at the same time, it was just absolutely seamless. Three or four mediums, this was to a bunch of Year 4 or 5's I think..... it was incredible, seamless.

The reference in the above quotation to multiple, simultaneous activities and the use of the word 'seamless' point to an understanding that combines sequence, complexity and flow. This contrasts with the idea of the lesson as recipe (Column 3) since a recipe implies that relationships between ingredients are fixed before the lesson begins, rather than open to change during it. 
In Table 1.0, BTs' conceptions of purpose of a successful lesson are presented in Rows A C. BTs with conceptions in Row A (i.e. Conceptions A1, A2, A3 or A4) demonstrated the most straightforward understanding. They recognised that successful lessons had a purpose but did not go beyond euphemisms such as 'progress', 'learning' or 'positive outcomes' in defining this. For example, one BT said that 'if I praise my students a lot for doing the right things, that means that I am confident with what they took out of the lesson and I am happy with their progress'. This BT uses three ways of describing the purpose of this lesson ('doing the right things', what students 'took out' and 'progress') but at no point in either their interview or written responses revealed any more detailed understanding. On further probing at interview, this BT, alongside many others, explained one euphemism by using another: the circularity of their argument confirming the nature of their understanding.

For BTs with conceptions in Row A, the purpose was often treated more as an unproblematic background issue, with BTs approaching it simply as one factor to consider amongst many others. For example, one BT wrote that 'the level of engagement was very high, the LOs (Learning Objectives) achieved and the behaviour was really good - a really successful lesson'. This quotation does not suggest that this BT gave any more weight to the achievement of learning objectives than to any other aspect of the lesson.

By contrast, another BT wrote:

The prerequisite of a successful lesson is therefore a strong plan where I have thought about the lesson from the point of view of the end objectives, rather than just a series of tasks to keep them busy for an hour. A successful lesson also has key questions embedded e.g. a lesson on breakeven delivered recently went off-plan, however it got pupils to understand the big point which is that a fixed cost changes, so the definition of it fixed relates to what causes it to change, as opposed to it have to be fixed permanently.

In the first sentence in the above quotation, this BT presents the purpose of the lesson (its 'end objectives') as something that should be embedded in all aspects of the lesson. This is indicative of a complex, layered view of a successful lesson. In the second sentence, the idea of 'big questions' is treated in a similar way. The implication is that 'big questions' are present in either the background of the teachers' awareness or in the foreground in their lesson plans (the BT does not indicate which) and act as guiding principles in the lesson, drawing all the different parts together. This BTs response is atypical of the sample in this study in that it gives a concrete example of deeper thinking (Row $C$ ) that is distinct from the acquisition of factual knowledge (Row B). The idea that a fixed cost is fixed in relation to the amount that a business sells, but is not fixed over time is conceptually challenging for school students because of the different meanings of the term 'fixed'. In saying that it is more important that 'big questions' in relation to fixed costs are addressed rather than that the plan is followed, this BT is integrating a high level understanding of structure and a high level understanding of purpose. In the context of the BTs' whole transcript, this is indicative of conception C4. 
In BTs' conceptions, the components of the structure were found to vary independently of the components of the purpose of the lesson. In other words, it was possible to have a high level understanding of the structure but a low level understanding of the purpose (and vice versa). For example, BTs with a linear sequencing conception revealed a variety of different understandings about the purpose of the lesson. One BT wrote that a successful lesson involved, 'introducing objectives at the start of the lesson and then going back to the objectives allowing the students to see their learning progress'. This BT displays a notion of sequencing but a low level understanding of the purpose of the lesson, indicative of conception A2. The BT above with a focus on the importance of plenary activities said that these would 'show whether the students have absorbed the information for the later exams and tests'. This suggests a focus on the acquisition of knowledge (Row B). By contrast, another BT who outlined the sequence of the successful lesson explained the importance of deeper thinking, defining this in terms of making connections between different topics in the subject:

Successful lessons are as such because they .... require students to think deeply about the topic. This indicates them not only engaging with the type of task and understanding the content, but going further than this and making synoptic links.

In a similar way, BTs with a living system conception also demonstrated different understandings of the purpose of the lesson. The quotation from the BT above who explained deeper thinking by referring to fixed costs illustrated conception C4. By contrast, another BT described the key indicator of a successful lesson as 'whether the learning outcomes have been met, if progress has been made (and) whether students feel they have learnt something' whilst then explaining that:

I am constantly checking whether my tasks/strategies are working. If students don't seem to be following, I automatically try to adapt this in the lesson there and then.

This BT seems to express a basic understanding of the purpose of the lesson alongside a more sophisticated understanding of the structure. This suggests that conception A4 might best describe their understanding.

\section{Discussion}

The ways of thinking about the purpose of the successful lesson suggested in this study are in tune with the learning aspects of conceptions described in earlier studies (e.g. Prosser et al., 2005; Paakari et al., 2011; Taylor \& Booth, 2015). Prosser et al. (2005) identify 4 'referential' categories of which 'concept acquisition' and 'information transfer' are similar to 'acquiring knowledge' in this study, and conceptual 'development' and 'change' are similar to 'developing deeper thinking'. Taylor and Booth (2015), in their study of science BTs, provide evidence that the 'student role' is to receive knowledge (at the lowest level) and construct it at the highest level. Paakari et al. (2011) include the less sophisticated 'acquisition of knowledge' and the more sophisticated 'transformation of thinking' in their descriptions of BTs' conceptions of learning in health education. 
There are differences between the results of these studies and the conceptions described in Table 1.0. Prosser et al. (2005) found more categories, but collected data from experienced academics who are likely to have more fine grained understandings of learning. In their study of BTs, Paakari et al. (2011) also found more categories, including the development of personal meanings and personal growth that were not visible at all in the thinking of the BTs in this study. Assuming their absence was not a result of the different subject (economics/business as opposed to health education), it could be because of the focus on learning in the context of a successful lesson in this study, rather than in the wider context of learning in general (as in Paakari et al.). The lowest category in this study (achieving 'learning objectives') was not present in the other studies. BTs who displayed this trait had a basic understanding that a lesson should have a purpose (which they labelled using educational jargon, such as 'learning' or 'progress') but did not have a deeper understanding of what that might mean.

These findings suggest that teacher educators need to take account of the following in the way in which they work with BTs: i) the relative coarseness of BTs' understanding of the purpose of a successful lesson (even at a point half way through their postgraduate programme), ii) the way in which BTs' wider understanding of learning is independent of their understandings of a successful lesson and, iii) the importance of being alive to the possible differences between the words that BTs use and the meanings they attach to them (particularly in relation to the purpose of a successful lesson).

The BTs in this study saw the structure of a successful lesson as a system in which components interacted in increasingly complex ways. At the lowest level BTs' understood the successful lesson as a disconnected set of parts. In the middle they saw it in terms of connections between those parts. At the highest level they saw it more as a 'complex adaptive system' (Capra \& Luisa, 2014). These are systems which are able to re-balance in the light of both internal and external changes and strike a balance between order and chaos, without losing their integrity. Complex adaptive systems are described as being in some way 'alive' in a similar way to the conceptions identified in Column 4 in Table 1.0. Variation in the quality of BTs' conceptions reflects the findings in other studies of systems in educational contexts. For example in a non-phenomenographic study of school students' conceptions of technological systems, a distinction was found between an atomistic, a systemic and a holistic understanding (Hallstrom \& Klasander, 2017). A phenomenographic study of the same phenomenon also highlighted differences between an unintegrated and an integrated understanding of the interconnections between components (Svensson \& Ingerman, 2010).

This study suggests that a more sophisticated understanding of a successful lesson is most likely to be achieved if teacher educators conceptualise the lesson as a system. This implies that approaches which represent 'a discipline for seeing wholes' (Senge, 2006) could be useful, such as systems theory (Capra \& Luisi, 2014). In this study, it was the nature of the relationships between components of a successful lesson that accounted for the categorical difference between BTs' understandings rather than the quantity of components. This implies that in their interventions, teacher educators' should prioritise relationships between components within the context of a whole lesson over knowledge of individual components. 
This study found that conceptions of a successful lesson consisted of qualitatively different understandings of both its purpose and of its structure. In other words, conceptions of learning are embedded within conceptions of a successful lesson. This means that it is not sufficient for the possession of a high level conception of a successful lesson that BTs have a sophisticated understanding of learning (or a sophisticated understanding of teaching); they also need a sophisticated understanding of the structure of a successful lesson.

In contrast to previous studies which have defined teaching and learning in terms of fixed relationships between components the evidence in this study is consistent with the existence of independent relationships between components. For example, for Prosser et al. (2005), it is only possible to have a higher conception of teaching and learning if a teacher has a high level understanding of both the act and the purpose of teaching. In this study, it has been shown to be possible for a BT to have a conception that combines a low level understanding of the structure of a lesson and a high level understanding of its purpose. This implies that there may be less of a connection between 'thinking' and 'doing' in relation to BTs' understanding of a successful lesson, than in their understanding of teaching and learning. Teacher educators need to adjust their expectations accordingly.

The conceptions identified in this study offer a way of thinking about what it means for a BT to learn about a successful lesson (if learning is defined as progressing from holding a less sophisticated to holding a more sophisticated conception). The grid of conceptions provides teacher educators with a framework for thinking about the development of BTs' understandings of a critical aspect of their teaching. It represents an addition to teacher educators' pedagogical content knowledge that could be applied at a macro level to the design of teacher education programmes and at a micro level to their day to day interactions with BTs. Since it highlights qualitative differences between conceptions, the grid of conceptions is also a tool for the diagnosis of BTs' current understandings and a way of setting developmental targets. Finally, phenomenography has been linked with variation theory (Marton, 2015). This theory explains how BTs might be encouraged to develop (by highlighting variation between conceptions in order to trigger the acquisition of more sophisticated conceptions). There is an emerging body of research pointing to the success of this approach in teacher education (e.g. Yee Lai \& Wah Presilla Lo-Fu, 2013; Cheng, 2014) alongside good evidence of its success in professional learning contexts in higher education (e.g. Rovio-Johansson, 2014).

The above arguments suggest that the structural relationships between phenomena should be considered when phenomenographers decide on a research focus in teacher education. However, it is not a requirement of phenomenographic research that these are considered. The choice is a result of exogenous factors, such as how difficult BTs perceive it is for students to learn (e.g. Davies \& Dunnill, 2008) or whether it has been studied before (e.g. Paakari et al., 2011). Applying these criteria to the choice of phenomenon runs the risk of ignoring important related phenomena that could have a controlling impact on the quality of BTs' teaching, such as the successful lesson.

The study has a number of limitations. Firstly, the grid layout of conceptions does not make it easy to determine the precise order of the hierarchy. For example, it is clear that 
A1 is less sophisticated than C4 but less clear whether A3 is equivalent to C2. This is a difficulty raised elsewhere (Durden, 2018). Secondly, although the study rigorously adhered to the principles and conventions of phenomenographic research, the results are still conditional on contextual factors such as: i) the subject of economics and business and the nature of its pedagogy and, ii) the characteristics of the English education system, including the organisation of teacher education. Further research would be required to confirm their generalisability.

\section{Conclusion}

This study has resulted in descriptions of qualitatively different conceptions of a phenomenon that has not previously been researched and is absolutely central to BTs' every day experience of teaching. The proposed hierarchy of conceptions adds to teacher educators' knowledge base by offering a framework for thinking about BTs' professional learning and how to organise it.

The study found that BTs' understanding of students' learning is embedded within their conceptions of a successful lesson and to some extent constrained by it. This finding is supported by previous phenomenographic research into the impact of context. The study also found that BT's understanding of the purpose of a successful lesson is not as fine grained as that proposed in other studies and that a systems approach to thinking about the structure of a successful lesson might be of benefit to teacher educators.

The two components of conceptions identified here suggest that it is not sufficient to develop BTs' thinking about teaching and/or learning, their understanding of a successful lesson should be considered too. Indirect evidence for this proposition comes from those studies that have not been able to identify a causal relationship between teachers' conceptions of teaching and learning and outcomes for students (e.g. Eley, 2002; Laksov et al., 2008). One possibility is that teachers' conceptions of teaching and learning are being mediated by their conceptions of a successful lesson (although further research would be required to confirm this).

\section{References}

Åkerlind, G. S. (2012). Variation and commonality in phenomenographic research methods. Higher Education Research \& Development, 31(1), 115-127. https://doi.org/10.1080/07294360.2011.642845

Ashworth, P., \& Lucas, U. (2000). Achieving empathy and engagement: a practical approach to the design, conduct and reporting of phenomenographic research. Studies in Higher Education, 25(3), 295-308. https://doi.org/10.1080/713696153

Biggs, J. (1996). Enhancing teaching through constructive alignment. Higher Education, 32(3), 347-364.

Boulton-Lewis, G. M., Brownlee, J., Berthelsen, D., \& Dunbar, S. (2008). Child care students' 
practical conceptions of learning. Studies in Continuing Education, 30(2), 119-128. https://doi.org/10.1080/01580370802097710

British Educational Research Association. (2011). Ethical Guidelines for Educational. London: BERA. https://doi.org/978-0-946671-32-8

Capra, F., \& Luisi, P. L. (2014). The systems view of life: a unifying vision. Cambridge: Cambridge University Press.

Chen, J., Brown, G. T. L., Hattie, J. A. C., \& Millward, P. (2012). Teachers' conceptions of excellent teaching and its relationships to self-reported teaching practices. Teaching and Teacher Education, 28(7), 936-947. https://doi.org/10.1016/J.TATE.2012.04.006

Cheng, E. C. K. (2014). Learning Study: nurturing the instructional design and teaching competency of pre-service teachers. Asia-Pacific Journal of Teacher Education, 42(1), 5166. https://doi.org/10.1080/1359866X.2013.869546

Cheng, M. M. H., Chan, K. W., Tang, S. Y. F., \& Cheng, A. Y. N. (2009). Pre-service teacher education students' epistemological beliefs and their conceptions of teaching. Teaching and Teacher Education, 25(2), 319-327. https://doi.org/10.1016/j.tate.2008.09.018

Davies, P., \& Dunnill, R. (2008). "Learning Study" as a model of collaborative practice in initial teacher education. Journal of Education for Teaching, 34(1), 3-16. https://doi.org/10.1080/02607470701773408

Desforges, C. (2015). Foreword. In P. Dudley (Ed.), Lesson Study: professional learning for our time (pp. $\mathrm{xv}-\mathrm{xx}$ ). London: Routledge, Taylor and Francis.

Durden, G. (2018). Accounting for the context in phenomenography-variation theory: evidence of English graduates' conceptions of price. International Journal of Educational Research, 87, 12-21. https://doi.org/10.1016/j.ijer.2017.11.005

Eley, M. G. (2006). Teachers' conceptions of teaching, and the making of specific decisions in planning to teach. Higher Education, 51(2), 191-214. https://doi.org/10.1007/s10734004-6382-9

Entwistle, N. (2007). Conceptions of learning and the experience of understanding: thresholds, contextual influences, and knowledge objects. In S. Vosniadou, A. Baltas, \& X. Vamvakoussi (Eds.), Reframing the conceptual change approach in learning and instruction (pp. 123-143). Oxford: Elsevier.

Eraut, M. (2000). Non-formal learning and tacit knowledge in professional work. British Journal of Educational Psychology, 70(1), 113-136. https://doi.org/10.1348/000709900158001

González, C. (2011). Extending research on "conceptions of teaching": commonalities and differences in recent investigations. Teaching in Higher Education, 16(1), 65-80. https://doi.org/10.1080/13562517.2010.507302

Hallström, J., \& Klasander, C. (2017). Visible parts, invisible whole: Swedish technology student teachers' conceptions about technological systems. International Journal of 
Technology and Design Education, 27(3), 387-405. https://doi.org/10.1007/s10798-0169356-1

Kember, D. (1997). A reconceptualisation of the research into university academics' conceptions of teaching. Learning and Instruction, 7(3), 255-275. https://doi.org/10.1016/S0959-4752(96)00028-X

Koballa, T., Graber, W., Coleman, D. C., \& Kemp, A. C. (2000). Prospective gymnasium teachers' conceptions of chemistry learning and teaching. International Journal of Science Education, 22(2), 209-224. https://doi.org/10.1080/095006900289967

Laksov, K. B., Nikkola, M., \& Lonka, K. (2008). Does teacher thinking match teaching practice? A study of basic science teachers. Medical Education, 42(2), 143-151. https://doi.org/10.1111/j.1365-2923.2007.02985.x

Lindblom-Ylänne, S., Trigwell, K., Nevgi, A., \& Ashwin, P. (2006). How approaches to teaching are affected by discipline and teaching context. Studies in Higher Education, 31(3), 285-298. https://doi.org/10.1080/03075070600680539

Marton, F. (2015). Necessary conditions of learning. London: Routledge.

Marton, F., \& Booth, S. (1997). Learning and awareness. Nahwah N.J.: Lawrence Erlbaum.

Marton, F., Dall'Alba, G., \& Beaty, E. (1993). Conceptions of learning. International Journal of Educational Research, 19, 277-300.

Paakkari, L., Tynjälä, P., \& Kannas, L. (2011). Critical aspects of student teachers' conceptions of learning. Learning and Instruction, 21(6), 705-714. https://doi.org/10.1016/j.learninstruc.2011.03.003

Prosser, M., Martin, E., \& Ramsden, P. (2005). Academics experiences of understanding of their subject matter and the relationship of this to their experiences of teaching and learning. Instructional Science, 33(2), 137-157.

Richardson, J. T. E. (1999). The concepts and methods of phenomenographic research. Review of Educational Research, 69(1), 53-82. https://doi.org/10.3102/00346543069001053

Rossum, E. J. Van, \& Hamer, R. (2010). The meaning of learning and knowing. Rotterdam/Boston/Taipei: Sense Publishers.

Rovio-johansson, A. (2014). An application of variation theory of learning in higher education. Theory and Method in Higher Education Research, 9, 261-279. https://doi.org/10.1108/S1479-3628(2014)0000010019

Senge, P. M. (2006). The fifth discipline: the art and practice of the learning organization. London: Random House Business Books.

Svensson, M., \& Ingerman, Å. (2010). Discerning technological systems related to everyday objects: mapping the variation in pupils' experience. International Journal of Technology and Design Education, 20(3), 255-275. https://doi.org/10.1007/s10798-009-9084-x

Swinkels, M. F. J., Koopman, M., \& Beijaard, D. (2013). Student teachers' development of 
learning-focused conceptions. Teaching and Teacher Education, 34, 26-37.

https://doi.org/10.1016/J.TATE.2013.03.003

Taylor, D. L., \& Booth, S. (2015). Secondary physical science teachers' conceptions of science teaching in a context of change. International Journal of Science Education, 37(8), 1299-1320. https://doi.org/10.1080/09500693.2015.1035356

Tigchelaar, A., Vermunt, J. D., \& Brouwer, N. (2014). Patterns of development in secondcareer teachers' conceptions of teaching and learning. Teaching and Teacher Education, 41, 111-120. https://doi.org/10.1016/j.tate.2014.04.001

Trigwell, K. (2000). A phenomenographic interview on phenomenography. In J. Bowden \& E. Walsh (Eds.), Phenomenography (pp. 62-82). Melbourne: RMIT University Press.

Trigwell, K., \& Prosser, M. (1996). Changing approaches to teaching: a relational perspective. Studies in Higher Education, 21(3), 275-284.

https://doi.org/10.1080/03075079612331381211

Trigwell, K., Prosser, M., \& Waterhouse, F. (1999). Relations between teachers' approaches to teaching and students' approaches to learning. Higher Education, 37, 57-70.

Tsai, C., \& Kuo, P. (2008). Cram school students' conceptions of learning and learning science in Taiwan. International Journal of Science Education, 30(3), 353-375. https://doi.org/10.1080/09500690701191425

Wilhelmsson, N., Dahlgren, L. O., Hult, H., \& Josephson, A. (2011). On the anatomy of understanding. Studies in Higher Education, 36(2), 153-165.

https://doi.org/10.1080/03075070903514054

Wood, K. (2000). The experience of learning to teach: changing student teachers' ways of understanding teaching. Journal of Curriculum Studies, 32(1), 75-93.

https://doi.org/10.1080/002202700182862

Yee Lai, M., \& Wah Priscilla Lo-Fu, Y. (2013). Incorporating learning study in a teacher education program in Hong Kong: a case study. International Journal for Lesson and Learning Studies, 2(1), 72-89. https://doi.org/10.1108/20468251311290141

Yung, B. H. W., Zhu, Y., Wong, S. L., Cheng, M. W., \& Lo, F. Y. (2013). Teachers' and students' conceptions of good science teaching. International Journal of Science Education, 35(14), 2435-2461. https://doi.org/10.1080/09500693.2011.629375 